International Journal of Linguistics, Literature and Translation

ISSN: 2617-0299 (Online); ISSN: 2708-0099 (Print)

DOI: 10.32996/ijltt

Journal Homepage: www.al-kindipublisher.com/index.php/ijltt

\title{
Translation of Biblical and Mythological Allusions in Three Shakespearean Tragedies: Hamlet, Macbeth, and Romeo and Juliet
}

\author{
Habib Alimardani ${ }^{1}$ 8(D) $\triangle$ and Esmail Zare-Behtash ${ }^{2}$ \\ ${ }^{7}$ Master of Arts in Translation Studies, Chabahar Maritime University, Chabahar, Iran \\ ${ }^{2}$ Associate Professor, Chabahar Maritime University, Chabahar, Iran \\ $\square$ Corresponding Author: Habib Alimardani, E-mail: habib.alimardani@gmail.com
}

\author{
ARTICLE INFORMATION \\ Received: August 11, 2021 \\ Accepted: September 05, 2021 \\ Volume: 4 \\ Issue: 9 \\ DOI: $10.32996 /$ ijllt.2021.4.9.4
}

\section{KEYWORDS}

Culture-specific items, biblical allusions, mythological allusions, translation strategies

\section{ABSTRACT}

Allusions as a literary device are included in a text to express meanings that go beyond the mere words the author uses and depend to a large extent on familiarity to be comprehended. Thus, they carry meaning in the culture in which they arise while this meaning is missed in another culture. The translation of allusions, therefore, which includes two language cultures, requires enormous problem-solving skills and adoption of strategies allowing the translator to evoke more or less the same reaction as that of the source language audience (Leppihalme, 1997). This study explores the adoption of strategies by Pasargadi (1996) in translating allusions rooted in mythology and the Bible in three Shakespearean tragedies, i.e. Hamlet, Macbeth and Romeo and Juliet based on the classification suggested by Ruokonen (2010). The analysis of the results revealed that the translator made more frequent use of modifying than retentive strategies, $52.69 \%$ and $47.31 \%$ respectively. Further investigation of the translation strategies employed by the translator sheds greater light on the reliability of the classification by Ruokonen (2010) and results in a better grasp of how to guarantee as close an effect on the target text audience as the one created on the source text audience.

\section{Introduction}

\subsection{Literary translation}

Translation in general and literary translation specifically is a way of establishing intercultural communication between two cultures which are oftentimes wildly different and which sometimes overlap. As Blažyte and Liubiniene (2016) state the overlaps between the two cultures i.e. instances in which the cultures are closely related, do not bring about a significant problem in the task of translation; what, as a matter of fact, does is where the translator is expected to bridge the gap between the source language culture and that of the target language, which according to Daghoughi and Hashemian (2016) can bring about a fundamental difference between the effects that the source text and the target text can produce. The farther apart or the more alien these cultures are from each other, the more challenging the task of establishing communication and filling the gap between them.

One can arguably claim that literary translation is the domains in which the translator encounters the greatest number of challenges, among which one can refer to the problems arising from cultural differences between the two languages, the original writer's use of specialized vocabulary and word play, the original text's ambiguities as well as the dilemma of creating an accurate or artistic form (Cincotta, 1995). "One of the most difficult problems facing a translator is how to find lexical equivalents for objects and events which are not known in the target culture" (Larson, 1998: 163 cited in Chaal, 2019: 131). Scholars in translation studies have adopted a variety of terms to describe these cultural units; for instance, Aiexela (1997) and a number of other experts have adopted "culture specific items," while some others including Baker (1992), Newmark (2003) described them as "culture-bound phenomena/concepts" (cited in Blažytè and Liubinienè, 2016). In much similar way, Leppihalme (1997) uses

\section{K C AL-KINDI CENTER R D FOR RESEARCH AND} Your gateway to world-class research



Published by Al-Kindi Center for Research and Development, London, United Kingdom. Copyright (c) the author(s). This open access article is distributed under a Creative Commons Attribution (CC-BY) 4.0 license 
the term "culture-bound elements," declaring that allusion is one of these elements which pose great challenges in the task of translating a source text into a target text since the translator is expected to go beyond merely translating words and the success of an allusion in conveying meaning depends on the familiarity of the audience with the referent. Campbell (1994) asserts that "allusions invite us to select from our mental library, knowledge which is not in the text itself and without which the writer's intention will not be fully communicated" (p.19). This emphasizes the importance of the audience's role in the effectiveness and recognition of an allusion (cited in Alimardani, 2010: 34).

\subsection{Allusion}

Abrams (1999: 9) defines allusion as "a passing reference, without explicit identification, to a literary or historical person, place, or event, or to another literary work or passage." In Ruokonen's view (2016: 450) "An allusion is an intertextual reference that evokes another text (the referent) and conveys implicit meanings to readers who can recognise the referent and interpret the alluding text in relation to it." The definitions of allusion take advantage of the concept of reference as a guide in describing what an allusion is. William Irwin, also, accepts that allusion is a type of reference. As he mentions, we sometimes use allusion and reference synonymously without drawing any distinction between them; nevertheless, in effect, there is a difference between allusion and reference (Irwin, 2001). Likewise, Leddy (1992), referring to language use, mentions that allusion is something beyond a mere reference. The distinction between an allusion and a reference is that in order to understand the proper meaning of an allusion the reader requires more than mere supplanting of a referent. Allusion involves certain associations and information not possessed and perceived by all people to the same extent. Thus, an allusion is indirect in the sense that it requires more than a mere substitution of a referent (ibid.).

One of the problems the translators encounter during the process of translation arises from the author's employment of allusions. According to Leppihalme (1997: 66) "while some allusions are transcultural (shared by both source and target culture), many others are culture-specific, and can only be understood by people sufficiently familiar with the culture in question." To put it differently, translation of allusion as a figures of speech and also as a culture-bound-term (CBT) is a challenging experience for translators since an allusive term or phrase does not merely involve denotative meanings rather connotative or implicit meanings imbedded in the allusive terms, which if neglected by the translator, the target reader will not register the allusion and even may be completely confounded by it. This is where according to Leppihalme (1997) a "culture bump" occurs; in other words, the target reader will fail to receive the same impact that SL created on its readers. Thus, the translator needs to adopt appropriate strategies in order to cope successfully with the problem at hand.

\subsection{Translation strategies for allusions}

As Leppihalme (1992) declares, a responsible translator is not supposed to allow his or her target text audience to become perplexed by ambiguous phrases or sentences which result from mistranslation or under-translation of allusive terms. The translator as a bicultural mediator must decide what translation strategy, considering the function of an allusion, works best in rendering the allusion. Leppihalme (1997) has provided a set of potential strategies for dealing with allusions. She divided allusions into two major categories of proper-name allusions and key-phrase allusions for each of which she introduced a series of potential translation strategies, on the basis of which Ruokonen (2010: 132-164) offered her own version of potential strategies for dealing with allusions. In her categorization of these possible strategies, she still adopts the terms "proper name" and "key-phrase" allusions; nevertheless, she organizes her categorization on the basis of translation strategies not the aforementioned terms. Basically, she divides the strategies, based on how much the translation departs from the source text, into two general classes of "retentive strategies" and "modified strategies." You can find Ruokonen's classification in greater detail below.

A) Retentive strategies

1) Replication

1a) KP retained untranslated, in exactly the same form as in the ST

1b) PN retained in exactly the same form as in the ST

1c) Adaptive replication: minor phonological, orthographic and morphologic adaptations not attributable to an existing translation

2) Minimum change: a literal translation not based on an existing translation

3) Existing translation: the TT passage resembles an existing TL translation, either exactly or with

minor modifications

Page | 37 
B) Modifying strategies

4) Adding guidance: the ST allusion is retained but complemented by an explanation about its meaning, source, etc.

5) Reducing guidance: the ST allusion is retained, but hints about its meaning, introductory

phrases, stylistic markers, etc., are reduced or omitted

6) Replacement: the ST allusion is replaced with another allusion

7) Omission: the ST allusion is omitted.

\section{Method}

The present research is an attempt on the part of the researcher to quantitatively analyze and describe the strategies which were adopted by Pasargadi, A. (1996) in translating proper-noun and key-phrase allusions which derived from mythology or the Bible in three Shakespearean tragedies, namely Hamlet (1600-1601), Macbeth (1606) and Romeo \& Juliet (1595). To attain this goal, the biblical and mythological allusions (54 proper-noun and 20 key-phrase allusions, i.e. a total of 74) in the aforementioned works and their corresponding Persian equivalents were identified, extracted and classified on the basis of the categorization provided by Ruokonen (2010).

\section{Results and discussion}

The problem with allusions also comes up in the translation of Shakespeare's tragedies where he makes frequent use of mythological and biblical proper-name and key-phrase allusions in order for such purposes as characterization and underlining the theme. Due to the essential role that the aforementioned types of allusion play in Shakespeare's works, the researcher came up with the idea of exploring how the Persian translators of these tragedies have dealt with such allusions and what strategies from those put forward by Ruokonen (2010) they have adopted in their translation of such allusion. Additionally, the researcher seeks to discuss what implications can be drawn from the translator's adoption of these strategies in their translation.

As the table below clearly illustrates strategy $1 \mathrm{~b}$, which represents retaining proper noun (PN) allusions, accounts for approximately $38 \%, 37.83 \%$ to be exact, of the cases translated. What this implies is the translator has simply retained the PN allusions without making an attempt to bring the allusive meaning of the nouns to the attention of the target text receiver. Retention of proper noun allusions is carried out for varied reasons one of which is the translator's failure in recognizing the allusion in the first place. Another reason one can think of with regard to mere retention of PN allusions can be the translator's lack of care about and attention to the significance of allusions in the development of the characters and the theme of a literary work. Nevertheless, one must bear in mind that retention of PN allusions is not necessarily unjustified, which is particularly the case with familiar PN allusions, the ones which the target text audience can easily recognize and grasp.

The second most frequently used strategy by Pasargadi (1996) in rendering allusions in the Shakespearean tragedies investigated was translating the allusions by adding guidance, which accounts for $31.08 \%$ of the cases studied. Pasargadi has sought to render 12 cases from among the 74 extracted allusive forms by carrying out a replacement, constituting $16.21 \%$ of the total cases investigated. In $13.51 \%$ of the cases, the translator replicated the allusive form by carrying out the necessary phonological or orthographic adaptations. Compared to all the previously pointed out strategies PN retention did not have much currency, which as the table clearly demonstrates only one of the proper noun allusions has been translated through this strategy.

\begin{tabular}{lcc}
\hline Adopted Strategy & Percentage & Frequency \\
\hline 1b: PN retained & $1.35 \%$ & 1 \\
\hline 1c: Adaptive replication & $13.51 \%$ & 10 \\
\hline 2: Minimum change & $37.83 \%$ & 28 \\
\hline 4: Adding guidance & $31.08 \%$ & 23 \\
\hline 6: Replacement & $16.21 \%$ & 12 \\
\hline
\end{tabular}

Table 1: the strategies adopted in translating the biblical and mythological allusions in detail

Ruokonen (2010) has classified the translation strategies into two general approaches of retentive and modifying strategies. In order to create a clear picture of the frequency of use of each one of these two general approaches, the proportions in the 
relevant sub-groups were added up to each other, indicating that, at $52.69 \%$, modifying strategies had more currency, compared to $47.31 \%$ for retentive strategies (see figure 1 below).



Figure 1: general strategies employed in translating the biblical and mythological allusions

Ruokonen (2010) does not arrange the strategies based on the type of allusion; rather, she classifies them on the basis of the strategies the translator adopts. Nevertheless, as the corpus of the study consists of both proper-noun and key-phrase allusions, one may wonder which strategies were commonly employed to render proper nouns, and similarly which ones were more frequently used to translate key-phrase allusions. The analysis of the cases reveals that Pasargadi has adopted five strategies in translating the proper-noun allusions, i.e. retention, adaptive replication, minimum change, adding guidance and replacement. As for the key-phrase allusions, the writer has adopted two strategies, that is adding guidance and minimum change.

From among the strategies adopted, as figure 2 illustrates, to render the PN allusions, at $38.88 \%$, adding guidance was the most frequently adopted strategy. The adoption of this strategy can be a rather tricky job since if the translator provides guidance about a familiar allusion, he or she may end up offending the target audience's intelligence by overtly translating an allusive form which has been included to carry meaning by connotation. The second most frequently adopted strategy here, at $22.22 \%$, was replacement. The translator adopted adaptive replication, in which a noun is adapted to the phonological and orthographical conventions of the target language, as frequently as minimum change, at $18.51 \%$. Pasargadi adopted retention the least often; only one of the cases has been translated this way.

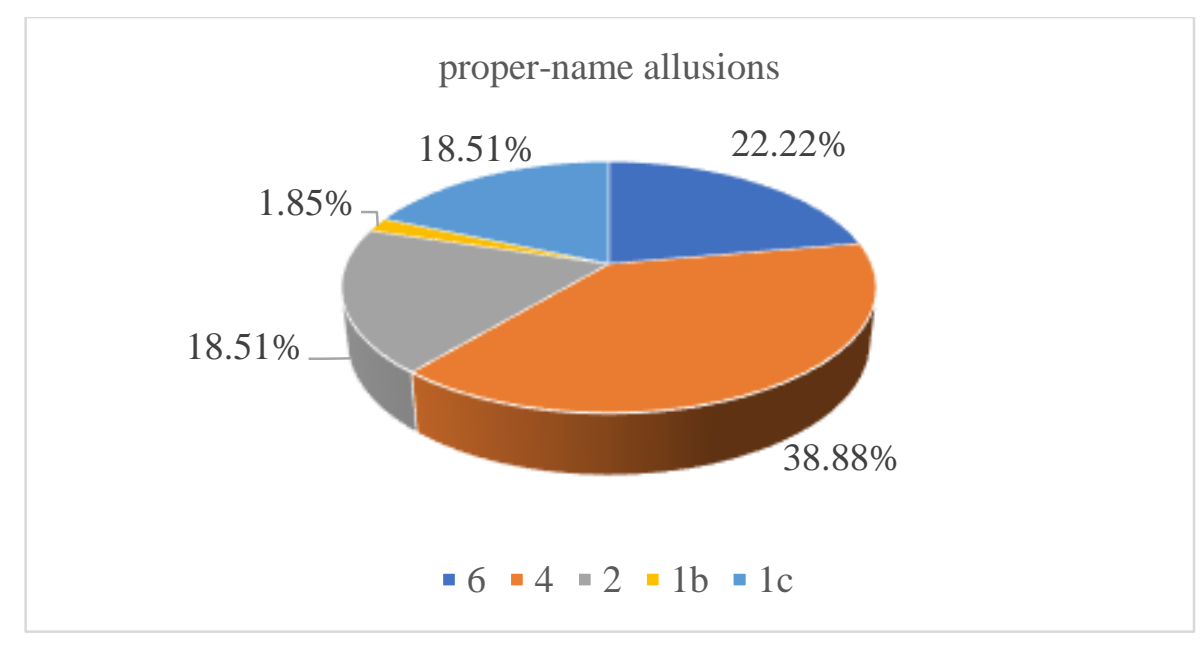

Figure 2: the strategies adopted in rendering PN allusions

On the other hand, merely two strategies have been employed in rendering key-phrase allusions, namely minimum change and adding guidance, with the majority of the cases, $80 \%$, being translated through minimum change (see figure 3). An excuse for favoring minimum change over the other strategies is as a translator you are not supposed to say everything. This assumption often leads to incomprehensible stretches of language. Minimum strategy as Leppihalme (1992) states works well with familiar allusions but with unfamiliar ones it is bound to result in culture bumps. If an allusion is unfamiliar the translator can try 
providing guidance in such a way that does not ruin the audience's joy and experience of recognizing an allusion and grasping its connotations.

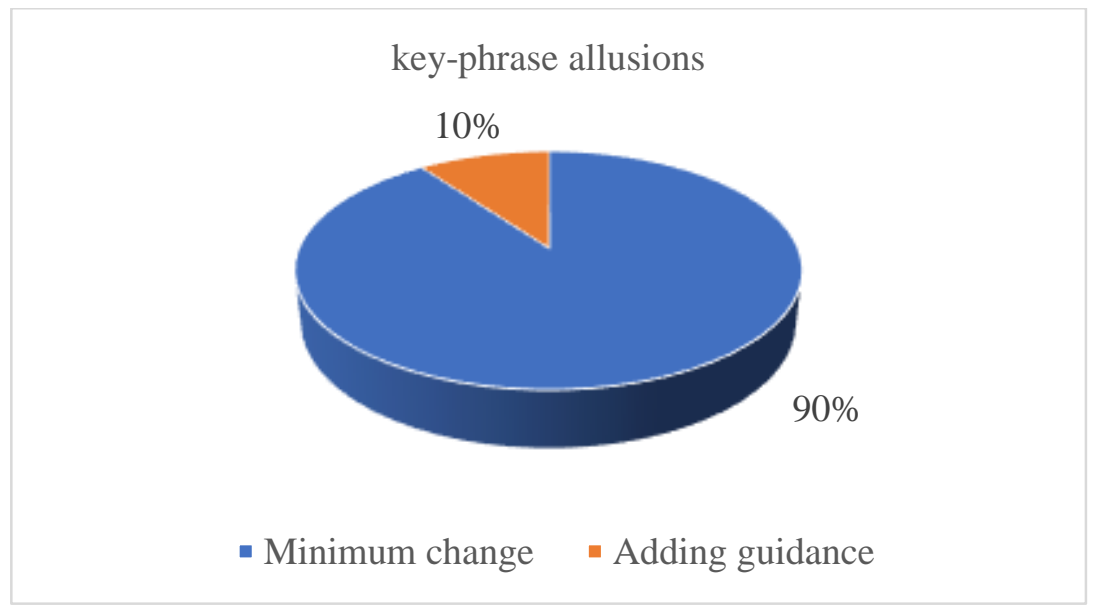

Figure 3: the strategies used in translating KP allusions

\section{Conclusion}

Allusions are based on the assumption that the audience is familiar with the referent; however, when translating these allusive forms in a culture which is relatively or fundamentally different form the original text, the translator encounters an immense barrier on the way of evoking a more or less similar impact on the target text audience. As a result, it is critically important that the translator be cognizant of the repertoire of strategies he or she can employ in rendering these allusive forms. The present study explored the adoption of strategies by Pasargadi (1996) in translating PN and KP allusions based on a classification offered by Ruokonen (2010).

The strategies, which the previously mentioned translator adopted, can be divided into two general types of retentive and modifying strategies, with each group involving a number of subcategories. What the researcher of the present paper found out within the process of analyzing the strategies and fitting them into Ruokonen's classification was that firstly the boundaries between the strategies in the classification were rather vague; there were cases which could fit into two classes. Secondly there were a few cases in which the translator had combined two strategies.

Apart from the ambiguity of the classification in some cases, the investigation indicated that modifying strategies had more frequency than retentive ones. From among the strategies which can fit into retention, minimum change had the greatest frequency, while as for modifying strategies adding guidance proved to be the most commonly used strategy. The analysis of the cases which were translated through adding guidance indicated that Pasargadi (1996) provided his guidance by getting help from footnotes, which is sometimes criticized as distractive or inconvenient. Translation of allusions can be a tricky job since if the translator provides guidance about a familiar allusion, he or she may end up offending the target text audience's intelligence by overtly translating an allusive form which has been included to carry meaning by connotation. On the other hand, if he or she merely retain an allusion or omit it entirely, he or she may end up creating an ambiguous or perplexing phrase or sentence which the audience will have to skip. This is, as a matter of fact, what happened with a considerable number of translated cases by Pasargadi; he has translated the majority of the key-phrase allusions through minimum change, which fits into retention strategies, resulting, considering the noticeable cultural distance between Persian and English, in many of the biblical key-phrase allusions losing their connotative meaning.

One must not forget that preserving all the associations in translation is unachievable; despite this, it behooves on the translator to feel more responsible to his or her audience and not to ruin the joy of recognizing a well-developed allusion by the audience. On the one hand the responsible translator must strive as much as possible not to let allusions go unnoticed; on the other hand, allusions are meant to allude instead of directly declaring something. Thus, the researcher is of the opinion that the translator can make sure the connotative meanings of allusions are preserved without ruining the joy of recognizing allusions through the use of endnotes, what was missing in all the three translations. 


\section{References}

[1] Abrams, M. H. (1999). A Glossary of Literary Terms. Fort Worth: Holt, Reinhart and \& Wilson Inc.

[2] Alimardani, H. (2010). Translation of Mythological and Biblical Proper-Name \& Key-Phrase Allusions in Three Shakespearean Tragedies: Hamlet, Macbeth, Romeo \& Juliet. [M.A. thesis, Chabahar Maritime University].

[3] Blažytè, D., and Liubinienè, V. (2016). Culture-Specific Items (CSI) and their Translation Strategies in Martin Lindstrom Brand Sense. Studies about Languages, 29, 42-57. doi: 10.5755/j01.sal.0.29.15129

[4] Campbell, J. (1994). Allusions and Illusions. French Studies Bulletin, 52 (15), 18-20.

[5] Chaal, H. (2019). Literary translation difficulties: Cultural Barriers. In Darir, H. (Ed.), Literary Translation from Translation to Creativity, (pp130 - 143). Modern Books'World, Jordan.

[6] Cincotta, M. S. (1995). Literary translation: A personal perspective. Paper presented at the Conference on Interpreting and Translation, Sydney, New South Wales, Australia.

[7] Daghoughi, S., and Hashemian, H. (2016). Analysis of Culture-Specific Items and Translation Strategies Applied in Translating Jalal AlAhmad's by the Pen. English Language Teaching 9, no. 4, 171-185. doi: 10.5539/elt.v9n4p171

[8] Irwin, W. (2001). What is an Allusion. The Journal of Aesthetics and Art Criticism, 59 (3), 287-297.

[9] Leddy, M. (1992). The Limits of Allusion. British Journal of Aesthetics, 32 (2), 110-122.

[10] Leppihalme, R. (1992). Allusions and Their Translation. In Nyyssönen, H. and Kuure (Ed.), Acquisition of Language-Acquisition of Culture, (pp.183-191).

[11] Leppihalme, R. (1997). Culture Bumps: An Empirical Approach to the Translation of Allusions. Clevedon: Multilingual Matters.

[12] Pasargadi, A. (1996). The Complete Works of William Shakespeare. Soroush press.

[13] Ruokonen, M. (2010). Cultural and textual properties in the translation and interpretation of allusions. An Analysis in Dorothy L. Sayers" detective novels translated into Finnish in the 1940s and the 1980s. University of Turku, English Translation.

[14] Ruokonen, M. (2016). Analysing Translated Allusions: Exploring a Statistical Approach. Paper presented at VAKKI Symposium XXXVI. Finland, February 11-12. 